\title{
Retraction Note: Characteristics of urban groundwater pollution based on abnormal data processing and optimization of sports health market
}

\author{
Ke Wang ${ }^{1}$
}

Published online: 22 November 2021

(c) Saudi Society for Geosciences 2021

Retraction Note: Arabian Journal of Geosciences (2021) 14: 1688 https://doi.org/10.1007/s12517-021-08016-z

The Editor-in-Chief and the Publisher have retracted this article because the content of this article is nonsensical. The peer review process was not carried out in accordance with the Publisher's peer review policy. The author has not responded to correspondence regarding this retraction.

The original article can be found online at https://doi.org/10.1007/ s12517-021-08016-z.

Ke Wang

wangke8511@126.com

1 Institute of Physical Education, Baise University,

Bai Se 533000, Guang Xi, People's Republic of China 